\title{
Correction: Empyema necessitans and a persistent air leak associated with rupture of an anaerobic lung abscess due to bacteroides
}

Sharma V, Blyth KG. Empyema necessitans and a persistent air leak associated with rupture of an anaerobic lung abscess due to bacteroides. Thorax 2018;73:91-3. doi: 10.1136/ thoraxjnl-2017-210462.

Figure 1 of this paper was published in print with the colours inverted. This makes the annotation of the figures (black/white arrow, black/white asterix) stated in the figure legend incorrect. Please find the correct figure and legend below.

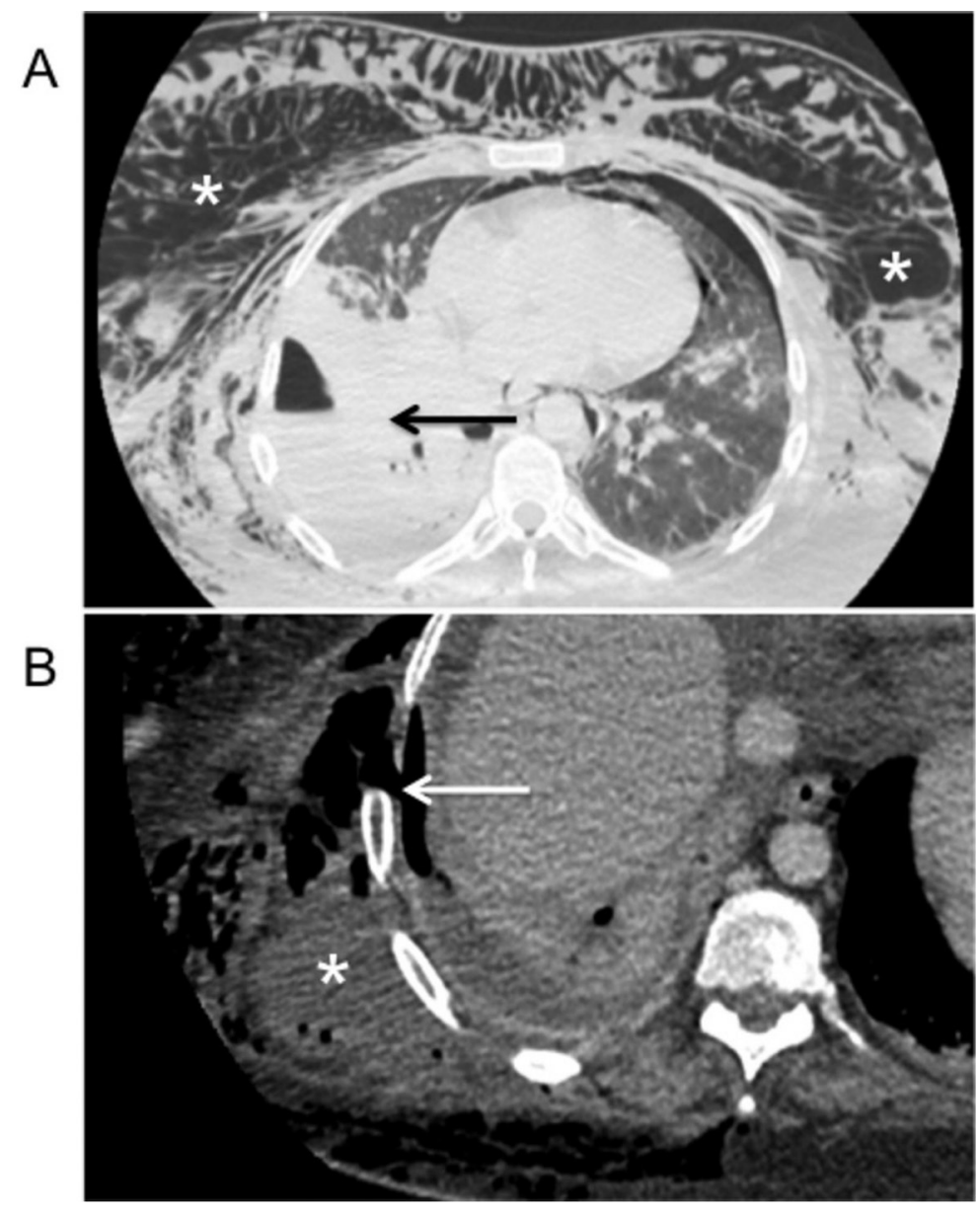

Figure 1 CT images (lung settings (A), mediastinal settings (B) acquired in a female patient with empyema necessitans (EN) and a persistent air leak related to a ruptured right lower lobe lung abscess. Extensive subcutaneous emphysema is highlighted in panel A (white asterix), which also shows right lower lobe lung consolidation (black arrow), an adjacent hydropneumothorax, a small left pneumothorax and a pneumomediastinum. Panel B shows a defect in the parietal pleura and subpleural tissues (white arrow), resulting in discharge of infected pleural fluid into the subcutaneous tissues (EN, white asterix).

(C) Article author(s) (or their employer(s) unless otherwise stated in the text of the article) 2018. All rights reserved. No commercial use is permitted unless otherwise expressly granted.

Thorax 2018;73:404. doi:10.1136/thoraxjnl-2017-210462corr1

(D) Check for updates 